\title{
Inflammatory and cytotoxic effects of acrolein, nicotine, acetylaldehyde and cigarette smoke extract on human nasal epithelial cells
}

\author{
David M Comer ${ }^{1,2}$, Joseph Stuart Elborn ${ }^{1,2+}$ and Madeleine Ennis ${ }^{1 *+}$
}

\begin{abstract}
Background: Cigarette smoke induces a pro-inflammatory response in airway epithelial cells but it is not clear which of the various chemicals contained within cigarette smoke (CS) should be regarded as predominantly responsible for these effects. We hypothesised that acrolein, nicotine and acetylaldehyde, important chemicals contained within volatile cigarette smoke in terms of inducing inflammation and causing addiction, have immunomodulatory effects in primary nasal epithelial cell cultures (PNECs).
\end{abstract}

Methods: PNECs from 19 healthy subjects were grown in submerged cultures and were incubated with acrolein, nicotine or acetylaldehyde prior to stimulation with Pseudomonas aeruginosa lipopolysaccharide (PA LPS). Experiments were repeated using cigarette smoke extract (CSE) for comparison. IL-8 was measured by ELISA, activation of NF-KB by ELISA and Western blotting, and caspase-3 activity by Western blotting. Apoptosis was evaluated using Annexin-V staining and the terminal transferase-mediated dUTP nick end-labeling (TUNEL) method.

Results: CSE was pro-inflammatory after a $24 \mathrm{~h}$ exposure and $42 \%$ of cells were apoptotic or necrotic after this exposure time. Acrolein was pro-inflammatory for the PNEC cultures $(30 \mu \mathrm{M}$ exposure for $4 \mathrm{~h}$ inducing a 2.0 fold increase in IL-8 release) and also increased IL-8 release after stimulation with PA LPS. In contrast, nicotine had anti-inflammatory properties ( 0.6 fold IL-8 release after $50 \mu \mathrm{M}$ exposure to nicotine for $24 \mathrm{~h}$ ), and acetylaldehyde was without effect. Acrolein and nicotine had cellular stimulatory and anti-inflammatory effects respectively, as determined by NF-KB activation. Both chemicals increased levels of cleaved caspase 3 and induced cell death.

Conclusions: Acrolein is pro-inflammatory and nicotine anti-inflammatory in PNEC cultures. CSE induces cell death predominantly by apoptotic mechanisms.

Keywords: Nasal epithelium, Cigarette smoke extract, Acrolein, Nicotine, Acetylaldehyde, Apoptosis

\section{Background}

Nasal and sinus inflammation is common in chronic obstructive pulmonary disease (COPD) and contributes to the decline in lung function [1]. The responses of the bronchial epithelium to cigarette smoke (CS) have been well characterised [2], but effects on the nasal epithelium, also important in respiratory disease, are not as well understood. Sinonasal symptoms in COPD range from $75 \%$ [3] to as much as $88 \%$ [4]. The most commonly

\footnotetext{
*Correspondence: m.ennis@qub.ac.uk

${ }^{\dagger}$ Equal contributors

${ }^{1}$ Centre for Infection and Immunity, Health Sciences Building, School of Medicine, Dentistry and Biomedical Sciences, Queen's University of Belfast, 97 Lisburn Road, Belfast BT9 7BL, UK

Full list of author information is available at the end of the article
}

reported upper airway symptoms are rhinorrhea, nasal obstruction and sneezing [3,5]. Overall, these observations confirm that significant sinonasal inflammation is present and important in COPD and in smokers [6]. Therefore, dissecting the effects of cigarette smoke on nasal epithelial cells is important in terms of our understanding of inflammation and COPD.

Although CSE is widely used in cell culture research it is an imperfect tool, having been criticised as a poor substitute for the prolonged, chronic exposure of tobacco smoke to which many smokers are exposed [7]. Recently investigators have opted to study individual components of CS [8-10]. The inherent complexity of CSE makes it difficult to identify any individual chemical 
mediating a particular cellular effect of interest. Furthermore, it is difficult to understand the relevance of any particular CSE concentration and duration of exposure. Even if inferences are made on the basis of findings from CSE data, these experiments do not duplicate in an entirely satisfactory manner all of the components that exist in vivo.

CSE has been reported to decrease basal IL-8 in alveolar cell lines [11]. However, other groups have demonstrated that CSE can have stimulatory properties in alveolar cell lines $[11,12]$ and in primary human macrophages [13] and to heighten the release of IL-8 in submerged healthy bronchial epithelial cell cultures after stimulation [14]. These discrepant findings in alveolar cell lines are almost certainly a result of the different concentrations of CSE used, with lower concentrations stimulating cells and higher concentrations being anti-inflammatory. It is however much more difficult to provide a valid explanation for the inconsistent findings in the primary cell research. Although there is no consensus in relation to the propensity for tobacco smoke to induce a pro-inflammatory response in bronchial epithelial cells, the weight of evidence, on balance, would support a pro-inflammatory [2,15-17] as opposed to an anti-inflammatory effect $[18,19]$.

Despite the diverse chemicals contained within cigarette smoke, its acute effects on cell function and toxicity appear to be due largely to volatile thiol-reactive components, of which acrolein is most abundant and reactive [20]. A toxicological risk assessment of the chemical constituents of cigarette smoke indicated that acrolein and acetylaldehyde had the highest overall non-cancer risk index for respiratory disease [21]. In vivo studies demonstrate that acrolein may be responsible for many of the respiratory responses to cigarette smoke exposure. For example, an acute exposure to acrolein diminishes pulmonary defence against bacterial and viral infection in animals [22,23], and a chronic exposure induces bronchial lesions and mucous hyperplasia [24]. Nicotine, a small molecule organic alkaloid, is another important constituent in cigarette smoke which not only is strongly related to addiction [25], but also is at least partially responsible for the airway irritation and inflammation induced by whole CS [26,27]. Acetylaldehyde, in concert with nicotine, contributes to addiction [28]. Furthermore, acetylaldehyde impairs mucociliary clearance in the lung, leading to an impaired host defense [29]. Therefore, acrolein, nicotine and acetylaldehyde are among the most important and relevant chemicals in cigarette smoke.

In addition to the activity of inflammatory cells in the airway, heightened proteolytic activity and greater levels of oxidative stress, an imbalance between apoptosis and proliferation of structural cells in the lung probably contributes to the pathogenesis of COPD [30].
The mechanism of cell death due to CSE exposure remains controversial [31,32]. In these experiments, we hypothesized that acrolein, nicotine and acetylaldehyde, known to be contained within CS, individually immunomodulate primary nasal epithelial cells (PNEC) cultures. CSE has been shown to be cytotoxic to nasal epithelial cell cultures [33], and we aimed to establish which, if any, of these individual chemicals were contributory.

\section{Methods}

\section{Study subjects and ethics statement}

Nasal brushings were obtained from 19 healthy volunteers. All 19 subjects were non-smokers, nor did any have chronic respiratory symptoms or require any therapy used for respiratory diseases. Bilateral nasal brushings were performed using a bronchial cytology brush (TeleMed Systems Inc., MA, USA) from the medial aspect of the inferior turbinate as previously described [34]. The brush was then removed and rinsed thoroughly in a $15 \mathrm{ml}$ polypropylene tube containing sterile PBS. Provided the patient tolerated the procedure, two brushings were obtained from each nostril. At the end of the procedure, DMEM medium containing 10\% Fetal Bovine Serum, Penicillin Streptomycin antibiotics (Invitrogen, USA) and Primocin (Invivogen, USA) was added. This study was approved by the Office for Research Ethics Committees Northern Ireland (REC: 09/NIR03/42) and all participants provided written informed consent.

\section{Cell culture and soluble mediator release}

PNECs were expanded in bronchial epithelial growth medium (BEGM, Promocell) with 100 units/ml Penicillin Streptomycin antibiotics (Invitrogen, USA) and $100 \mu \mathrm{g} /$ $\mathrm{ml}$ Primocin (Invivogen, USA). Cells were confirmed to be epithelial in origin by randomly staining cultures by immunocytochemical staining for cytokeratin expression (Figure 1). Cells (passage 2-3; $1 \times 10^{5}$ cells $/ \mathrm{ml}$ ) were seeded in purified bovine collagen coated (PureCol; Advanced Biomatrix) 12-well plates and cultured for 24 h. Cells were stimulated with LPS from Pseudomonas aeruginosa (Sigma-Aldrich), either with or without pretreatment with acrolein, nicotine or acetylaldehyde as outlined in the results section. Separate cultures were treated with 5\% CSE alone. After appropriate stimulation, cell-free supernatants were collected and stored at $-80^{\circ}$ for future IL-8 and IL-6 measurement using the Duoset ELISA kits (R\&D Systems) according to the manufacturer's instructions. Cells were used for protein expression studies.

\section{Immunofluorescence}

Cells were seeded on coverslips at a density of $1 \times 10^{5}$ cells $/ \mathrm{ml}$. The following day, cells were fixed in 4\% PFA and washed in PBS. After permeabilisation with $0.2 \%$ Triton-X 100 (Sigma, Dorset, UK), cells were treated 


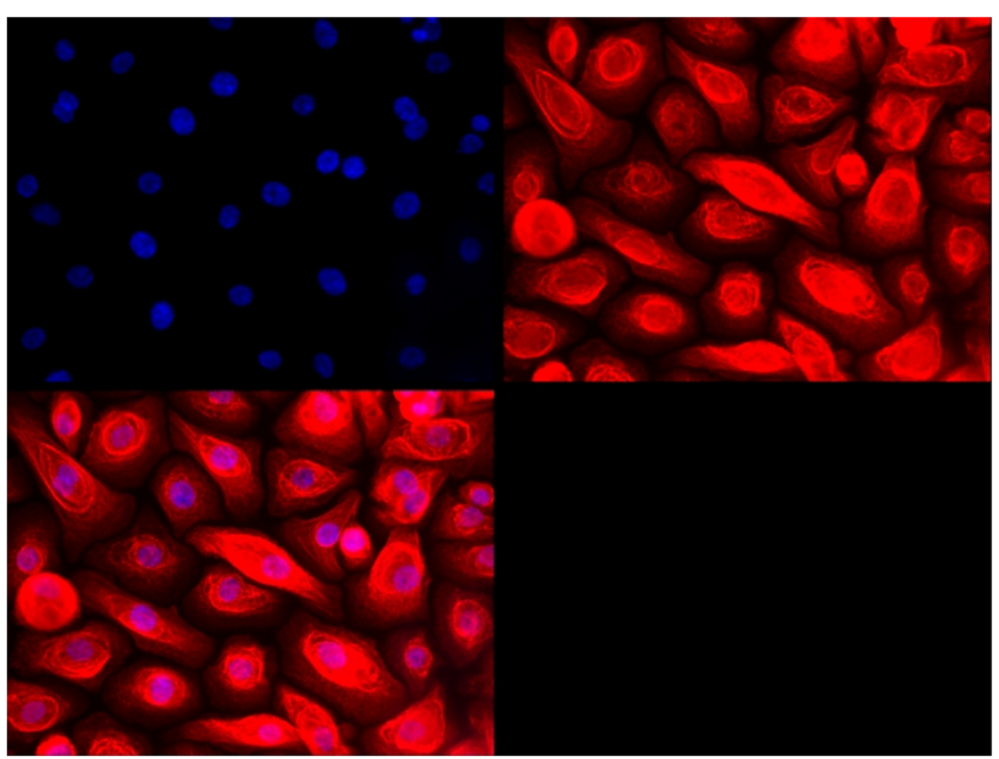

Figure 1 Immunocytochemistry for cytokeratin $\mathbf{5}$ in nasal epithelial cell cultures. Primary nasal epithelial cell cultures were stained with a rabbit anti-human antibody against cytokeratin 5 (1:100). The primary antibody was detected using a secondary antibody coupled to Alexafluor 568 (1:500). Nuclei were stained blue with DAPI ( $\times 40)$. Each quadrant represents DAPI staining alone (upper left), staining for cytokeratin 5 alone (upper right), and staining for both DAPI and cytokeratin 5 (lower left).

with a 1:100 dilution of rabbit anti-cytokeratin-5 primary antibody (Abcam, Cambridge, UK) overnight at $4^{\circ} \mathrm{C}$. The primary antibody was detected using a 1:500 dilution of Alexafluor 568 goat anti-rabbit IgG (Invitrogen Ltd., Paisley, UK). Nuclei were stained with DAPI (Vector Laboratories, Peterborough, UK). Images were captured using LAS AF (Leica) acquisition software.

\section{CSE preparation}

CSE was prepared by a modification of the method of Richter et al. [17] One commercial Marlboro Red cigarette (0.8 mg nicotine; $10 \mathrm{mg}$ Tar; $10 \mathrm{mg}$ carbon monoxide) was combusted with a modified syringe-driven apparatus. The smoke was bubbled through $25 \mathrm{ml}$ of media over 5 min by drawing 35-ml volume of smoke every $15 \mathrm{~s}$. The resulting suspension was filtered through a $0.2 \mu \mathrm{m}$ pore-size filter to remove large particles and bacteria. This solution was regarded as "100\% CSE" and freshly generated for each experiment, and subsequently serially diluted with culture medium to obtain a final $5 \%$ working concentration. The optical density was constant when comparing a series of 5\% CSE solutions prepared in this manner [35].

\section{Annexin-PI staining}

Apoptosis was analysed using Annexin V (Av) and Propidium Iodide (PI) staining (eBioscience, UK). Events which were negative for Av and PI were considered to represent viable cells, those positive for Av, but negative for PI represented early apoptosis and events positive for both Av and PI secondary necrosis. To eliminate debris from the analysis the discrimination level was set to 100 . Cells, adjusted to $1 \times 10^{5}$ cells per $100 \mu \mathrm{l}$, were suspended in binding buffer and incubated with the fluorochrome-conjugated Av for $15 \mathrm{~min}$. Subsequently, after washing, cells were re-suspended in fresh binding buffer and stained with PI. In order to set gates and establish appropriate compensation settings, cells were stained with PI alone, Av alone, and both PI and Av. In order to obtain positive control samples for early apoptosis and necrosis respectively, cells were treated with $5 \mu \mathrm{M}$ staurosporin and $0.1 \%$ Triton-X respectively for $4 \mathrm{~h}$.

\section{TUNEL assay}

After treating PNECs with individual chemicals as described in the results section, cultures were analysed for apoptosis using the Click-It TUNEL assay (Invitrogen, UK). Cells, after being fixed and permeabilised, were exposed to a reaction cocktail overnight at room temperature. Cells were then treated with a reaction buffer additive mixture for $30 \mathrm{~min}$, and cells mounted onto glass coverslips with mounting media and DAPI. Images were captured using LAS AF (Leica) acquisition software.

\section{Western blotting}

For Western blotting, cells were lysed in radioimmunoprecipitation assay buffer (Sigma-Aldrich, UK). The protein concentration was determined by BCA protein assay kit (Fisher Scientific, UK). Equal amounts of protein $(15 \mu \mathrm{g} /$ lane) were separated in a 10\% SDS gel, and transferred to a polyvinylidene difluoride sheet by electroelution with a 
constant voltage of $100 \mathrm{~V}$ for $90 \mathrm{~min}$ at room temperature. After blocking with $0.1 \%$ Tween 20 supplemented with PBS (T-PBS) containing skimmed milk, the sheet was incubated with a 1:1,000 dilution phosho-NF-kB antibody (Cell Signalling, UK) at $4^{\circ} \mathrm{C}$ overnight. The sheet was then washed three times with T-PBS, and incubated with goat HRP conjugated anti-rabbit antibody (1:3,000 dilution; Abcam, UK) for $1 \mathrm{~h}$ at room temperature. After washing with T-PBS three times, immunoreactive protein bands were revealed with an enhanced chemiluminescence western blot analysis system. After being "stripped" using a Western Blot Stripping Buffer (Thermoscientific, UK), membranes were re-probed with a polyclonal antibody against IKB- $\alpha$ and for beta-actin (both 1:1,000 dilution).

To determine the effects of individual chemicals on caspase- 3 activation in PNEC cultures, cultures were treated as described in the results section. For the detection of cleaved caspase-3, a 1:1,000 dilution of primary antibody was used (Cell Signalling, UK). The sheet was then washed three times with T-PBS, and incubated with goat HRP conjugated anti-rabbit antibody (1:3,000 dilution; Abcam, UK) for $1 \mathrm{~h}$ at room temperature and developed as described.

\section{TransAM NF-KB assay}

Nuclear extracts were prepared using a nuclear extraction kit from Active Motif (Belgium, UK) according to manufacturer's instructions. The Active Motif TransAM NF-kB ELISA kit (Belgium, UK) was used to determine the levels of p65 in nuclear extracts. In brief, $2 \mu \mathrm{g}$ of nuclear extract, diluted to $20 \mu \mathrm{L}$, was added to the wells coated with oligonucleotides containing the NF- $\mathrm{kB}$ consensus binding site. The primary antibodies used to detect NF- $\mathrm{KB}$ recognise an epitope on p65 that is accessible only when NF- $\mathrm{B}$ is activated and bound to its target DNA. After the addition of secondary antibodies conjugated with HRP and substrate, absorbance was read at $450 \mathrm{~nm}$ (with a reference wavelength at $650 \mathrm{~nm}$ ). In order to monitor for specificity, competitive binding assays were performed. Wild-type or mutated consensus oligonucleotides were added to the wells containing immobilised oligonucleotides before the addition of nuclear extracts.

\section{Statistics}

Statistical analysis was performed using SPSS version 17.0 (SPSS inc., Chicago, IL, USA). Data are presented as median values \pm interquartile range. Comparisons between groups were performed using the nonparametric Kruskal-Wallis test for multiple comparisons and the Mann-Whitney test for two groups. A $p$ value of less than 0.05 was considered significant.

\section{Results}

Soluble mediator release

Cells were confirmed to be epithelial by staining with cytokeratin-5 (Figure 1). Constitutive and stimulated release of IL- 8 and IL- 6 was used to determine PNEC activation. Pre-treating PNEC cultures with $30 \mu \mathrm{M}$ acrolein for $1 \mathrm{~h}$ or $4 \mathrm{~h}$ increased the basal constitutive release of IL-8, and heightened the release of IL-8 after subsequent stimulation with Pseudomonas aeruginosa LPS (PA LPS; Sigma-Aldrich, UK). This was statistically significant after a $4 \mathrm{~h}$ incubation period with acrolein (Figure 2). Repeating experiments using $50 \mu \mathrm{M}$ nicotine (Sigma-Aldrich, UK) demonstrated anti-inflammatory effects for the PNEC cultures after a $4 \mathrm{~h}$ and $24 \mathrm{~h}$ incubation period, although only reached statistical significance for the latter incubation period. $50 \mu \mathrm{M}$ acetylaldehyde (Sigma-Aldrich, UK) was without effect on cytokine release after a $4 \mathrm{~h}$ and $24 \mathrm{~h}$ incubation period. Treating PNEC cultures with CSE for $24 \mathrm{~h}$ heightened the release of IL-8 (Figure 2). In separate experiments, PNEC cultures were treated for $4 \mathrm{~h}$ with acrolein $(10-50 \mu \mathrm{M})$ which demonstrated a dose responsive increment in IL-8 release up to $30 \mu \mathrm{M}$ with evidence of cytotoxicity at higher concentrations determined using the MTT assay. Results for IL-6 followed a similar trend for all experiments (data not shown).

\section{Effects of acrolein, nicotine, acetylaldehyde and CSE on activation of caspase-3 in PNEC cultures}

Using an antibody against the cleaved fragment of caspase $3(17-19 \mathrm{kDa})$, we demonstrated by Western blotting that treatment with both acrolein and nicotine for $1 \mathrm{~h}$ increased levels of active caspase 3 , which was most pronounced for acrolein. Repeating experiments with acetylaldehyde for $1 \mathrm{~h}$ did not activate caspase 3 . A brief exposure for $1 \mathrm{~h}$ to $5 \%$ CSE cleaved caspase 3, in a concentration dependant manner (Figure 3).

\section{Effects of acrolein, nicotine, acetylaldehyde and CSE on cell viability in PNEC cultures}

Annexin-V staining demonstrated that $50 \mu \mathrm{M}$ nicotine exposure for $24 \mathrm{~h}$ induced predominantly early apoptosis in PNEC cultures. After treatment with $50 \mu \mathrm{M}$ acrolein for $4 \mathrm{~h}$, there was evidence of predominantly necrosis. Acetylaldehyde had minimal effects on cell viability, and $5 \%$ CSE for $24 \mathrm{~h}$ induced apoptosis and secondary necrosis. Events which were positive for apoptosis and necrosis are shown (Figure 4 and Table 1). Apoptosis was confirmed using the TUNEL assay for each stimulus (Figure 5).

\section{Effects of acrolein, nicotine, acetylaldehyde and CSE on NF-KB activation}

There was a significant increase in phosho-NF- $\mathrm{kB}$ protein levels after stimulation with $30 \mu \mathrm{g} / \mathrm{ml}$ acrolein for 


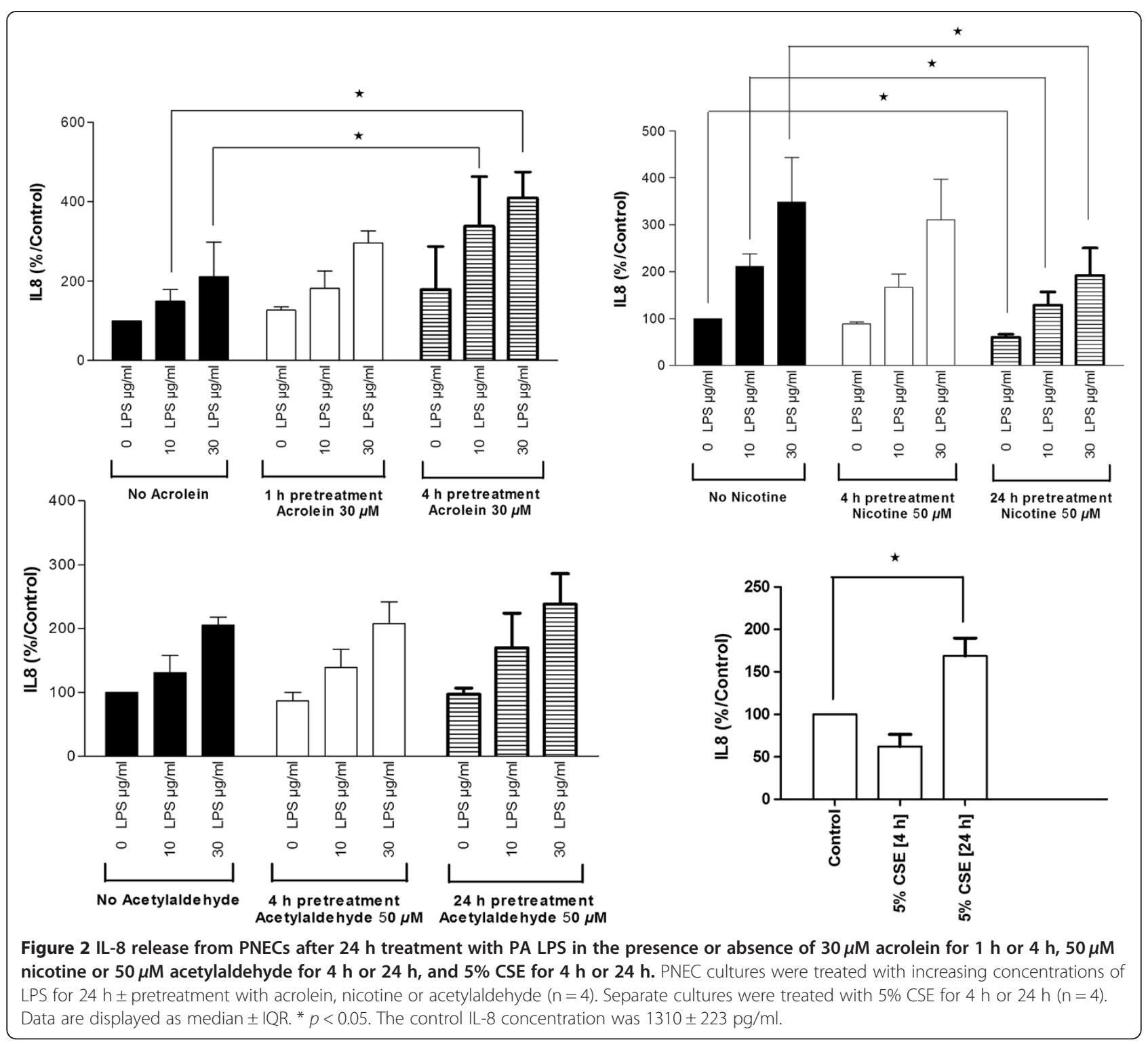

$1 \mathrm{~h}$, whereas $50 \mu \mathrm{M}$ nicotine for $1 \mathrm{~h}$ reduced phosho-NF$\kappa B$ protein concentration measured from whole cell lysates. Repeating experiments using $50 \mu \mathrm{M}$ acetylaldehyde had no effect on levels of phosho-NF- $\mathrm{BB}$. 50\% CSE height-

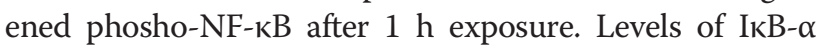
had an inverse relationship to phosho-NF- $\mathrm{kB}$ for all chemical stimulation (Figure 6). Repeating experiments and determining levels of active NF- $\mathrm{kB}$ p65 protein from nuclear extracts provided similar results (Figure 7).

\section{Discussion}

Acrolein is pro-inflammatory and nicotine anti-inflammatory in PNEC cultures. In contrast, acetylaldehyde was without effect on cytokine release. Nicotine induced predominantly early apoptosis in the cultures, whereas acrolein induced both apoptosis and overt necrosis. Interestingly, a study exposing PNECs to CSE for $1 \mathrm{~h}, 2 \mathrm{~h}$, and $4 \mathrm{~h}$ reported a time and dose-dependent cytotoxicity of CSE [33]. Nicotine and acrolein increased levels of active caspase 3; acrolein to a greater extent. Experiments were repeated with CSE, containing all of these chemicals, for comparison purposes. We exposed PNEC cultures to CSE for a $4 \mathrm{~h}$ and a $24 \mathrm{~h}$ period to facilitate comparison of our data with other published work. The concentrations of CSE used can range from 100\% CSE for 15 minutes [18] to a $1 \%$ CSE for 24 hours (in those studies which use a single cigarette to prepare the initial "100\%" stock CSE) [12]. CSE also cleaved full length caspase 3, induced early and late apoptosis after a $24 \mathrm{~h}$ exposure, and was pro-inflammatory after this exposure time. Acrolein and CSE increased, whereas nicotine reduced, levels of active NF-kB. 


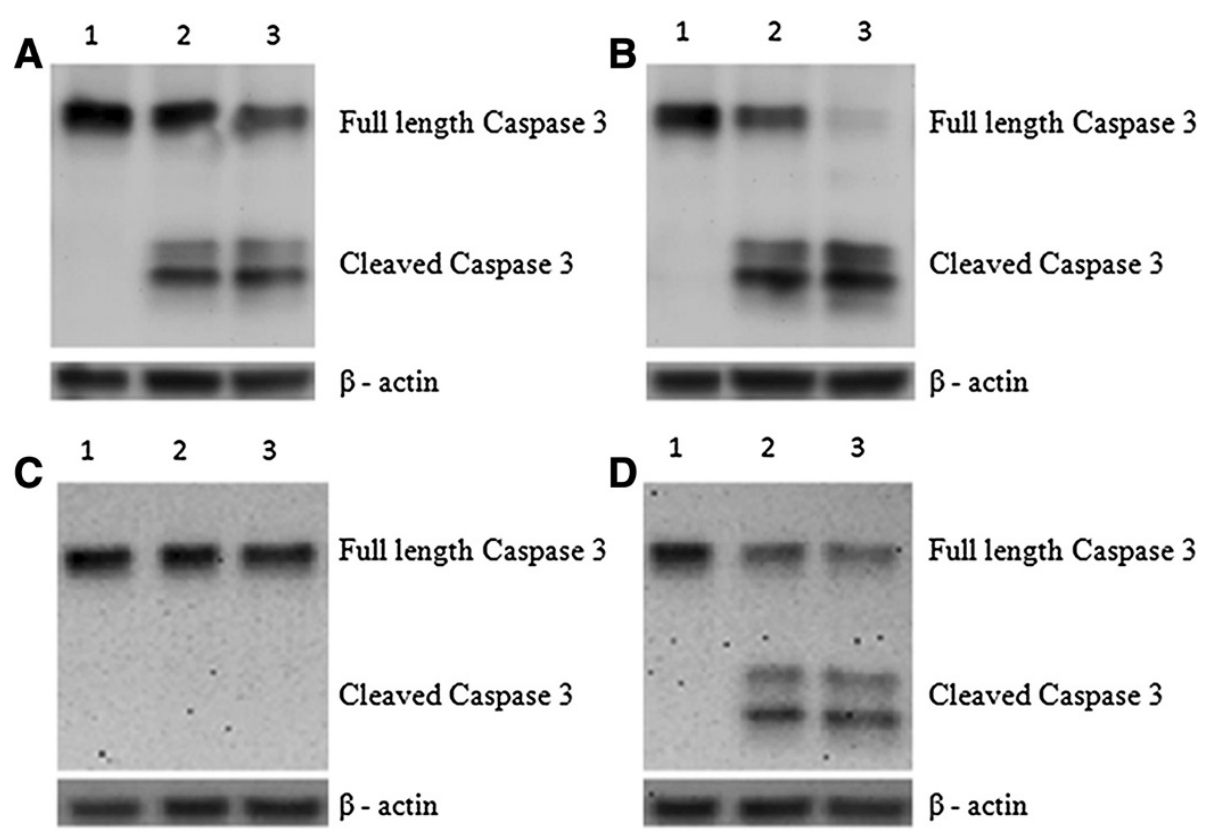

Figure 3 Effect of acrolein and nicotine on caspase-3 activation in PNEC cultures determined using western blotting. Western blots of cleaved caspase 3 in healthy PNECs (with beta-actin loading controls). Blot $\mathbf{A}$ : lanes 1-3 represent treatment of PNECs with 0, 5, 50 $\mu \mathrm{M}$ nicotine (1 h); blot B: lanes 1-3: 0, 10, $50 \mu \mathrm{M}$ acrolein (1 h); blot C: lanes 1-3 represent treatment of PNECs with 0, 5, $50 \mu \mathrm{M}$ acetylaldehyde (1 h) and blot D lanes 1-3: 0\%, 5\%, 50\% CSE (1 h) respectively.

Treating submerged or air liquid interface PNEC cultures with acrolein has been reported to suppress basal IL-8 release [36], and acrolein inhibited LPS-induced cytokine release from human alveolar macrophages when used at a $25 \mu \mathrm{M}$ concentration [37]. Furthermore, acrolein has been shown to reduce inflammatory responses in human bronchial epithelial cell lines by suppressing NF- $k B$ activation [38]. The report demonstrating anti-inflammatory properties of acrolein in PNEC cultures acquired samples from subjects with chronic rhinosinusitis, and so this may not reflect the activity of acrolein from the PNEC cultures. Furthermore, those reports indicating that acrolein had antiinflammatory properties on epithelial cells had both treated cultures for 30 minutes [36,38], whereas an $18 \mathrm{~h}$ exposure of acrolein in small airway epithelial cell cultures was pro-inflammatory when similar concentrations of acrolein were used [39]. Therefore, and as we have demonstrated in these experiments, it is clear that exposure time is an important determinant as to the effects of acrolein in airway epithelial cell cultures, as is the case for treatment with CSE.

Nicotine had no significant effect on LPS-induced IL-8 production in the CF cell line, CFTE29o [40], but suppressed inflammatory responses in human bronchial epithelial cell lines after stimulation with LPS [41]. Our data indicate that in healthy PNEC cultures, nicotine was anti- inflammatory. In contrast, Tsai et al. demonstrated that treatment of bronchial epithelial cell lines with nicotine induced IL-8 production, and this effect was mediated by both ERK and JNK MAPK, but yet not through the p38 pathway [42]. In their study the cell lines were exposed to nicotine for a shorter period of time $(4 \mathrm{~h}, 8 \mathrm{~h}, 10 \mathrm{~h})$ using a lower concentration $(5 \mu \mathrm{M})$. In our studies acetylaldehyde appears to have no role in terms of the immunomodulatory effects of CSE. The differences observed by previous investigators are likely to be a result of the different cell types used in their respective experiments.

The concentrations of nicotine and acrolein in the alveolar lining fluid in smokers are of the order of $30 \mu \mathrm{M}$ and $80 \mu \mathrm{M}$ respectively [43]. However, maximum stimulation of IL-8 was achieved in primary small airway epithelial cells after stimulation with $30 \mu \mathrm{M}$ acrolein for $18 \mathrm{~h}$, decreasing thereafter with higher concentrations, attributed to the cytotoxic effects of treatment [39]. Similar results have been reported using the human bronchial cell line, HBE1, with no detectable apoptosis using a flow cytometry method after exposure to $25 \mu \mathrm{M}$ acrolein for $12 \mathrm{~h}$, but clearly present with higher concentrations [44]. We also report that the optimal acrolein concentration is in the $30 \mu \mathrm{M}$ range for cell culture experiments, with a marked reduction in cell viability at $50 \mu \mathrm{M}$ using the MTT assay, rendering the release of IL-8 difficult to interpret at this particular concentration. 


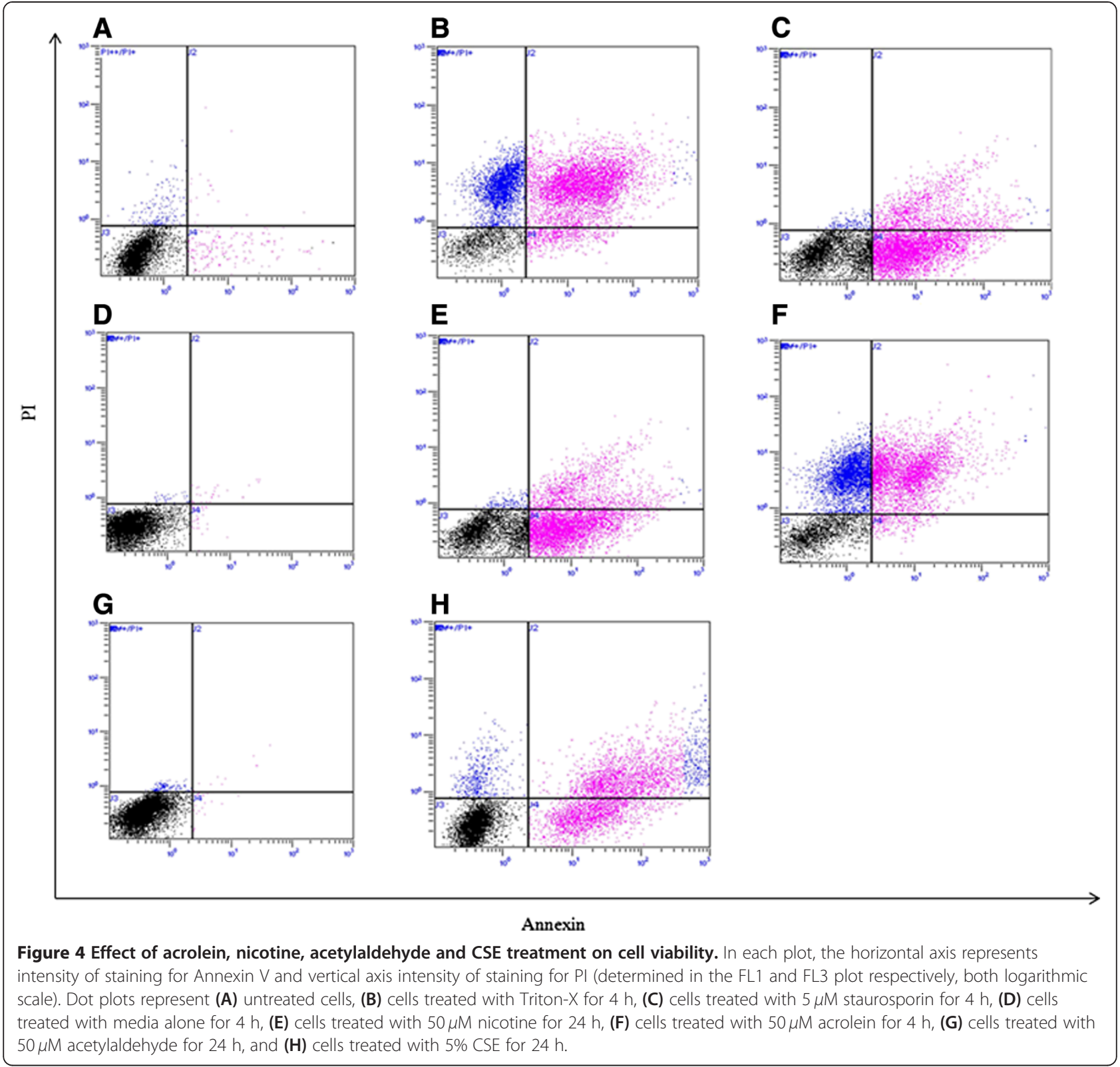

Table 1 Annexin-V/Propidium iodide analysis of acrolein, nicotine, acetylaldehyde and CSE treatment in PNEC cultures

\begin{tabular}{ccccc}
\hline & $\begin{array}{c}\text { Av (-) } \\
\text { PI (-) }\end{array}$ & $\begin{array}{c}\text { Av (+) } \\
\text { PI (-) }\end{array}$ & $\begin{array}{c}\text { Av (+) } \\
\text { PI (+) }\end{array}$ & $\begin{array}{c}\text { Av (-) } \\
\text { PI (+) }\end{array}$ \\
\hline Media 24 h & $99.1 \%$ & $0.4 \%$ & $0.4 \%$ & $0.1 \%$ \\
Nicotine 24 h & $39.7 \%$ & $45.5 \%$ & $13.0 \%$ & $1.8 \%$ \\
Acrolein 4 h & $26.3 \%$ & $2.2 \%$ & $39.8 \%$ & $31.7 \%$ \\
Acetylaldehye 24 h & $97.4 \%$ & $0.2 \%$ & $2.0 \%$ & $0.4 \%$ \\
5\% CSE 24 h & $51.8 \%$ & $19.1 \%$ & $25.6 \%$ & $3.5 \%$ \\
\hline
\end{tabular}

Percentages of events positive for apoptosis and necrosis are shown corresponding to dot-plots $\mathrm{D}-\mathrm{H}$ in Figure 4.
Nicotine has been reported to have anti-inflammatory effects in inflammatory bowel disease, and reduces inflammatory cytokine release in alveolar macrophages [45-47]. Previous studies have reported that nicotine exerts its anti-inflammatory function to activation of its receptor, nAChR, and as a consequence, inhibition of the NF- $\mathrm{kB}$ pathway $[48,49]$. Furthermore, nicotine has the potential to inhibit TLR-2 mediated inflammation in response to TLR-2 agonists in CF cell lines [40]. Unfortunately, the use of nicotine as a therapeutic agent is limited by its negative side effects including cardiovascular disease, hypertension, cancer and gastrointestinal disorders [50]. 

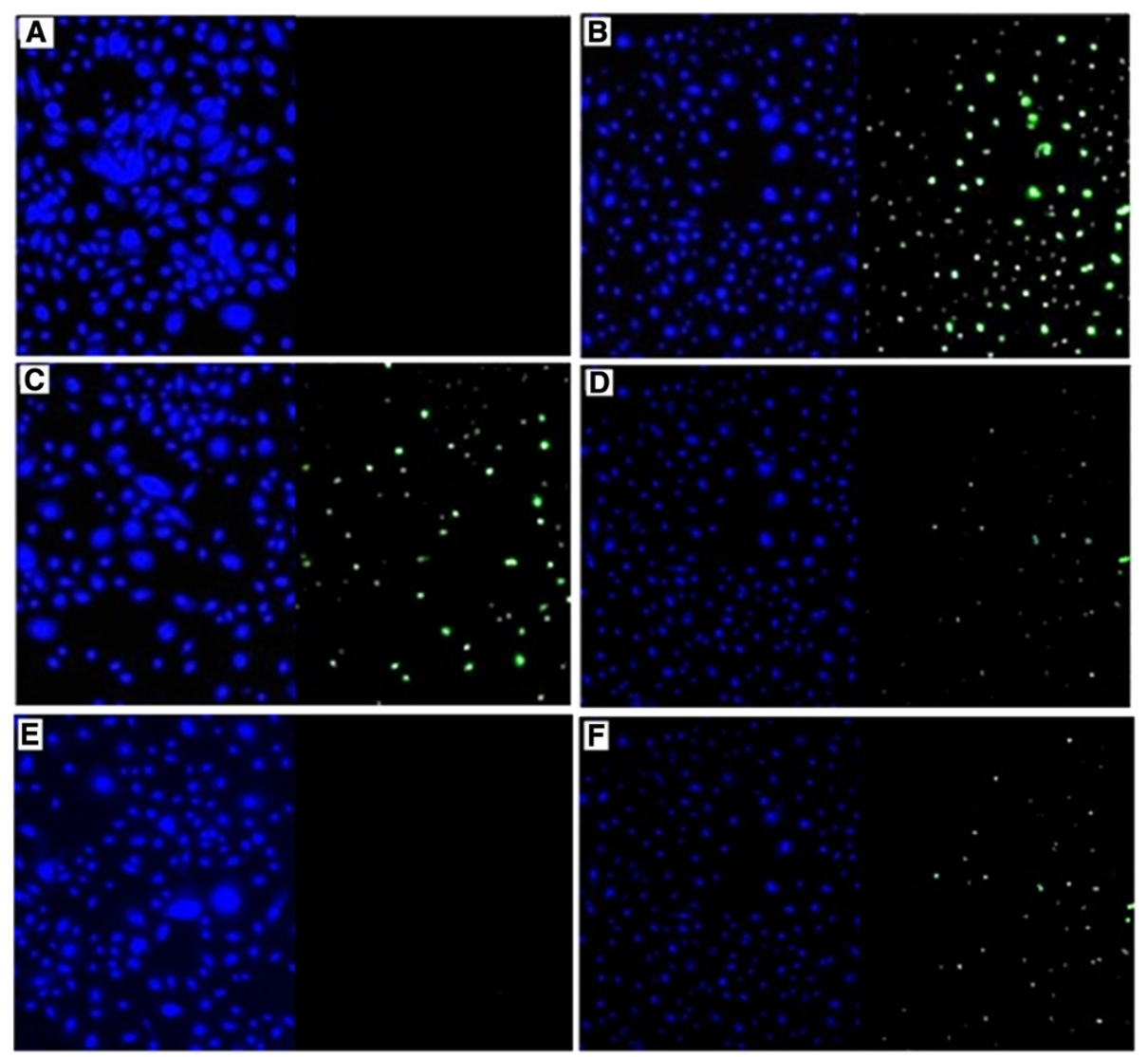

Figure 5 Effect of acrolein, nicotine, acetylaldehyde and CSE on apoptosis in PNEC cultures using TUNEL assay. Nasal epithelial cells were grown on coverslips and treated with (A) PBS or (B) DNase I solution for the negative and positive control respectively. Separate samples were treated with (C) $50 \mu \mathrm{M}$ acrolein for $4 \mathrm{~h}$, (D) $50 \mu \mathrm{M}$ nicotine for $24 \mathrm{~h}$, (E) $50 \mu \mathrm{M}$ acetylaldehyde for $24 \mathrm{~h}$ or (F) $5 \%$ CSE for $24 \mathrm{~h}$. Levels of apoptosis were determined using the Click-iT reaction according to manufacturer's instructions.

CSE has been reported to induce apoptosis in primary bronchial epithelial cells [51,52], and primary nasal epithelial cells [33], by some but not all investigators $[53,54]$. Interestingly, one group reported that cigarette smoke condensate (CSC) inhibited apoptosis, but yet caused necrosis in human umbilical vein endothelial cells [55]. Furthermore, recent research using primary bronchial epithelial cells indicated that CSE caused necrosis rather than apoptosis [56]. This group prepared CSE using $10 \mathrm{ml}$ of media, and so could be considered to be more than twice as concentrated when compared to our CSE preparation. In addition, the epithelial cells were exposed to the CSE for $48 \mathrm{~h}$, and so it is not particularly surprising that no apoptosis was evident as the cells had undergone necrosis. CSC, which also contains the lipid soluble fractions of volatile smoke, induces apoptosis in A549 cells [57]. It is difficult to relate this to other CSE preparations for comparison purposes, or to the in vivo airway of the smoker, but it provides evidence that apoptosis can be induced in cell culture with various aqueous CSE preparations. Interestingly, CSE induces cell death in bronchial smooth muscle cells which is blocked by the addition of $\mathrm{N}$-acetylcysteine [45].

The three methods we opted to use in order to determine the loss of cell viability, when considered in isolation, are not ideal. Although the TUNEL nick-end labeling method is increasingly applied to investigate active cell death, many investigators do not regard the technique to be acceptable $[55,58]$. It has been suggested that DNA fragmentation, which is the fundamental aspect which the TUNEL assay measures, is common to different types of cell death, and so on this basis it cannot itself be relied upon to specifically measure apoptosis [58]. Cell death can occur by mechanisms which are independent of caspase activity [59], and annexin- $\mathrm{V}$ staining can give false positives due to damage to the cell membrane induced during the detachment of the cells by trypsin/EDTA. However, despite the shortcomings of the individual assays, and taking all of the evidence together, our data indicate that acrolein, nicotine and CSE are inherently cytotoxic, and that CSE causes cell death by apoptotic mechanisms. 


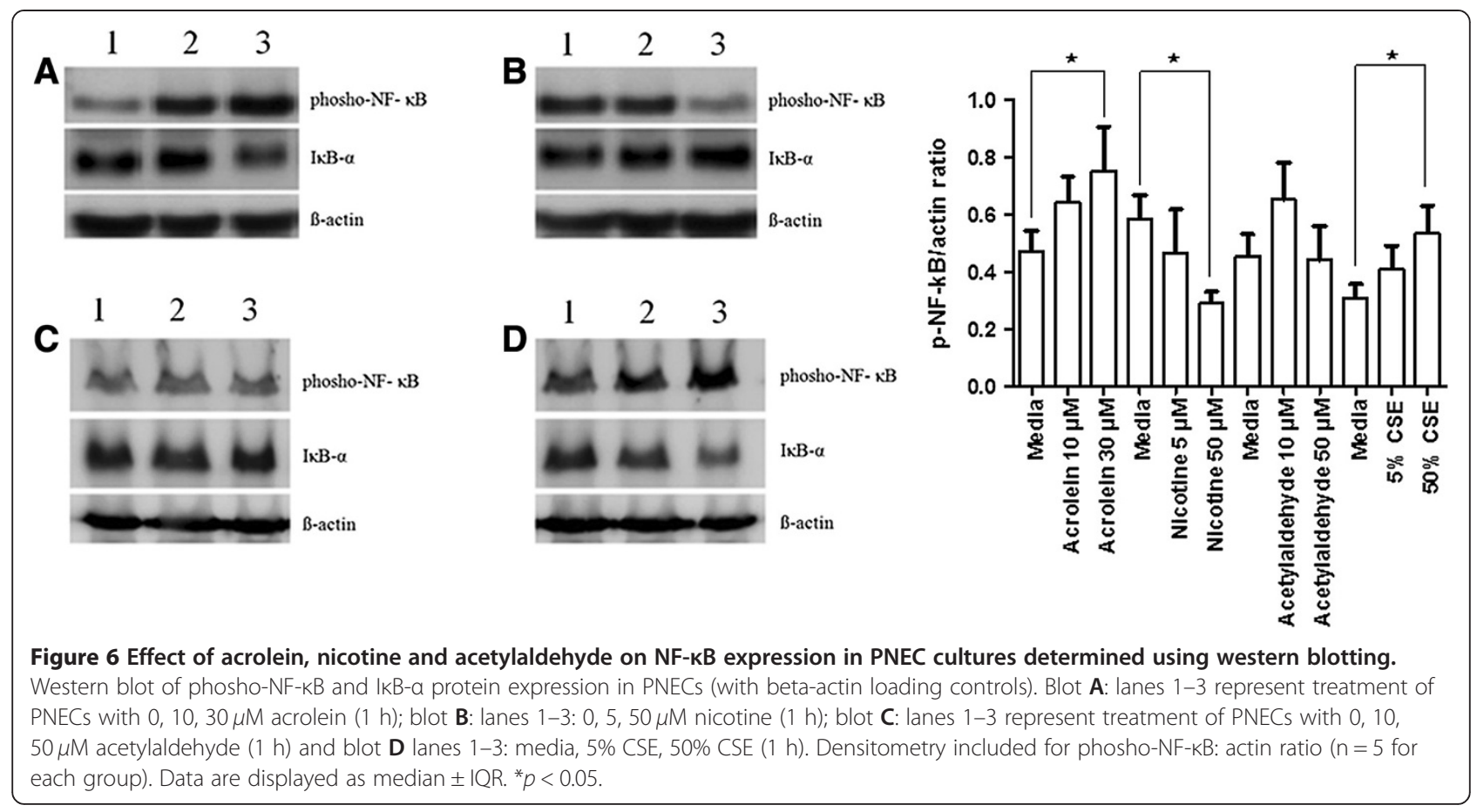

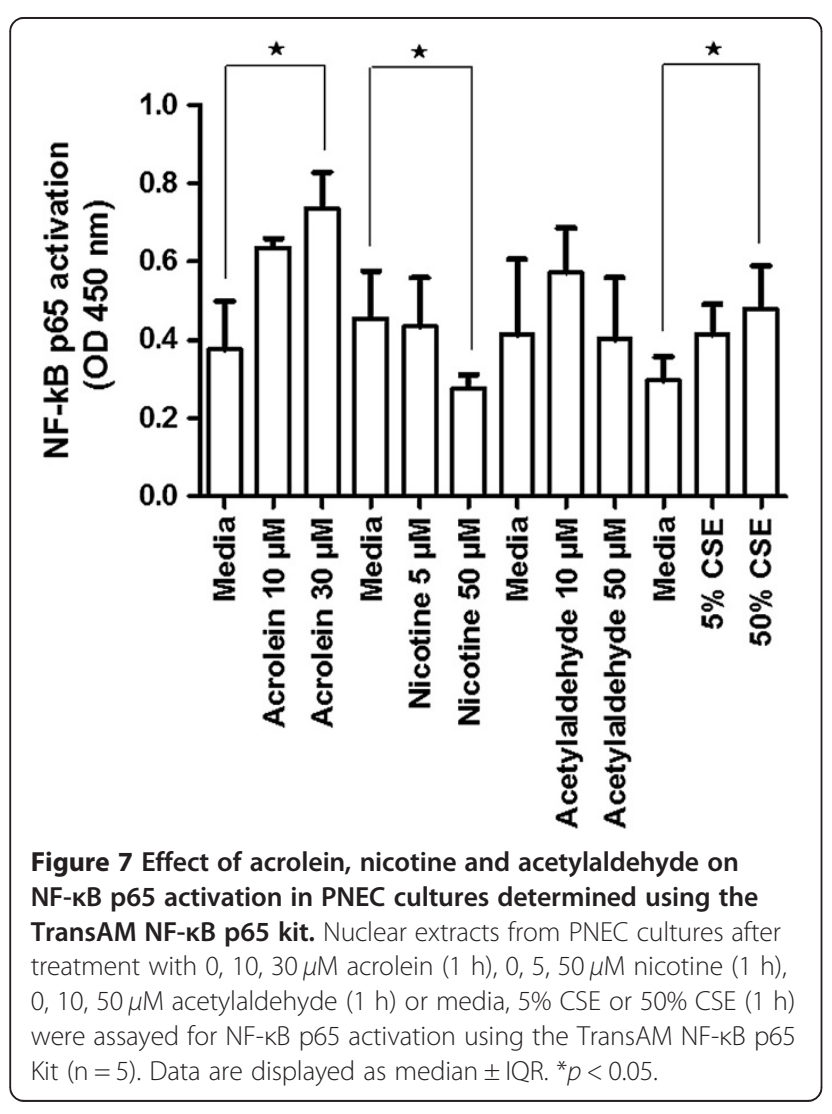

In contrast to our findings, other groups have demonstrated that CSE increased phosphorylated NF- $\mathrm{kB}$, induced DNA damage, yet was protective against apoptosis in BEAS-2B cells [54]. This may be attributable to the fact that cell lines were used and not primary cells, and also likely because a relatively brief 30 minute exposure of CSE was used, a much shorter duration to that which we adopted. Interestingly, acrolein induced apoptosis in the bronchial epithelial cells line, HBE1, which was attributed to the intracellular generation of oxidants [44].

\section{Conclusion}

Our data demonstrate that acrolein and nicotine, when used at concentrations which are of relevance in the airway of cigarette smokers, stimulate and immunosuppress PNEC cultures respectively. Acetylaldehyde, on the other hand, had no effect. Both acrolein and nicotine should be considered toxic substances to cell cultures, and particularly so for acrolein. As acrolein heightened IL-8 release, yet still caused loss of cell viability, this finding at least suggests that the reduced IL- 8 release after nicotine treatment cannot merely be attributed to loss of cell viability. This is supported by the reduced levels of phosho-NF- $\mathrm{kB}$ apparent after nicotine treatment. Finally, exposure to CSE heightened phosho-NF$\kappa B$ levels in the PNEC cultures. Overall our data confirm the understanding that CSE is cytotoxic, and that some of the chemicals contained within it can individually immunomodulate and induce cell death in PNEC cultures to varying degrees. 


\author{
Abbreviations \\ CS: Cigarette smoke; CSE: Cigarette smoke extract; CSC: Cigarette smoke \\ condensate; PNECs: Primary nasal epithelial cell cultures; PA \\ LPS: Pseudomonas aeruginosa lipopolysaccharide; TUNEL: Terminal \\ transferase-mediated dUTP nick end-labeling; COPD: Chronic obstructive \\ pulmonary disease.
}

\section{Competing interests}

The authors declare that they have no competing interests.

\section{Authors' contributions}

JSE, ME and DC conceived of the study, and participated in its design and coordination. DC carried out the laboratory work, recruited study subjects drafted the manuscript. JSE and ME also helped to draft the manuscript. All authors read and approved the final manuscript.

\section{Acknowledgements}

The authors would like to thank the Northern Ireland Research and Development Office for funding this study (REF: EAT/3978/08)

\section{Author details}

${ }^{1}$ Centre for Infection and Immunity, Health Sciences Building, School of Medicine, Dentistry and Biomedical Sciences, Queen's University of Belfast, 97 Lisburn Road, Belfast BT9 7BL, UK. ${ }^{2}$ Respiratory Department, Belfast City Hospital, Lisburn Road, Belfast BT9 7AB, UK.

Received: 10 April 2013 Accepted: 25 February 2014

Published: 1 March 2014

\section{References}

1. Kim JS, Rubin BK: Nasal and sinus inflammation in chronic obstructive pulmonary disease. COPD 2007, 4:163-166.

2. Mio T, Romberger DJ, Thompson AB, Robbins RA, Heires A, Rennard SI: Cigarette smoke induces interleukin- 8 release from human bronchial epithelial cells. Am J Respir Crit Care Med 1997, 155:1770-1776.

3. Roberts NJ, Lloyd-Owen SJ, Rapado F, Patel IS, Wilkinson TM, Donaldson GC, Wedzicha JA: Relationship between chronic nasal and respiratory symptoms in patients with COPD. Respir Med 2003, 97:909-914.

4. Hurst JR, Wilkinson TM, Donaldson GC, Wedzicha JA: Upper airway symptoms and quality of life in chronic obstructive pulmonary disease (COPD). Respir Med 2004, 98:767-770.

5. Montnemery P, Svensson C, Adelroth E, Lofdahl CG, Andersson M, Greiff L, Persson CG: Prevalence of nasal symptoms and their relation to self-reported asthma and chronic bronchitis/emphysema. Eur Respir J 2001, 17:596-603.

6. Lieu JE, Feinstein AR: Confirmations and surprises in the association of tobacco use with sinusitis. Arch Otolaryngol Head Neck Surg 2000 126:940-946.

7. Shapiro SD: Smoke gets in your cells. Am J Respir Cell Mol Biol 2004 31:481-482

8. Sarkar $\mathrm{P}$, Hayes BE: Induction of COX-2 by acrolein in rat lung epithelial cells. Mol Cell Biochem 2007, 301:191-199.

9. Zhang $\mathrm{H}$, Forman $\mathrm{HJ}$ : Acrolein induces heme oxygenase-1 through PKC-delta and PI3K in human bronchial epithelial cells. Am J Respir Cell Mol Biol 2008, 38:483-490.

10. McMaster SK, Paul-Clark MJ, Walters M, Fleet M, Anandarajah J, Sriskandan S, Mitchell JA: Cigarette smoke inhibits macrophage sensing of Gram-negative bacteria and lipopolysaccharide: relative roles of nicotine and oxidant stress. Br J Pharmacol 2008, 153:536-543.

11. Wang $J \mathrm{H}$, Kim H, Jang $\mathrm{YJ}$ : Cigarette smoke extract enhances rhinovirusinduced toll-like receptor 3 expression and interleukin-8 secretion in A549 cells. Am J Rhinol Allergy 2009, 23:5-9.

12. Witherden IR, Vanden Bon EJ, Goldstraw P, Ratcliffe C, Pastorino U, Tetley TD: Primary human alveolar type II epithelial cell chemokine release: effects of cigarette smoke and neutrophil elastase. Am J Respir Cell Mol Biol 2004, 30:500-509.

13. Koarai A, Yanagisawa S, Sugiura H, Ichikawa T, Akamatsu K, Hirano T, Nakanishi M, Matsunaga K, Minakata Y, Ichinose M: Cigarette smoke augments the expression and responses of toll-like receptor 3 in human macrophages. Respirology 2012, 17:1018-1025.
14. Floreani AA, Heires AJ, Welniak LA, Miller-Lindholm A, Clark-Pierce L, Rennard SI, Morgan EL, Sanderson SD: Expression of receptors for C5a anaphylatoxin (CD88) on human bronchial epithelial cells: enhancement of C5a-mediated release of IL-8 upon exposure to cigarette smoke. J Immunol 1998, 160:5073-5081.

15. Betsuyaku T, Hamamura I, Hata J, Takahashi H, Mitsuhashi H, Adair-Kirk TL, Senior RM, Nishimura M: Bronchiolar chemokine expression is different after single versus repeated cigarette smoke exposure. Respir Res 2008, 9:7.

16. Kode A, Yang SR, Rahman I: Differential effects of cigarette smoke on oxidative stress and proinflammatory cytokine release in primary human airway epithelial cells and in a variety of transformed alveolar epithelial cells. Respir Res 2006, 7:132.

17. Richter A, O'Donnell RA, Powell RM, Sanders MW, Holgate ST, Djukanovic R, Davies DE: Autocrine ligands for the epidermal growth factor receptor mediate interleukin-8 release from bronchial epithelial cells in response to cigarette smoke. Am J Respir Cell Mol Biol 2002, 27:85-90.

18. Laan M, Bozinovski S, Anderson GP: Cigarette smoke inhibits lipopolysaccharide-induced production of inflammatory cytokines by suppressing the activation of activator protein-1 in bronchial epithelial cells. J Immunol 2004, 173:4164-4170.

19. Li W, Xu YJ, Shen HH: Effect of cigarette smoke extract on lipopolysaccha-ride-activated mitogen-activated protein kinase signal transduction pathway in cultured cells. Chin Med J (Engl) 2007 120:1075-1081.

20. Leuchtenberger C, Leuchtenberger R, Zbinden I: Gas vapour phase constituents and $\mathrm{SH}$ reactivity of cigarette smoke influence lung cultures. Nature 1974, 247:565-567.

21. Fowles J, Dybing E: Application of toxicological risk assessment principles to the chemical constituents of cigarette smoke. Tob Control 2003 12:424-430

22. Li L, Holian A: Acrolein: a respiratory toxin that suppresses pulmonary host defense. Rev Environ Health 1998, 13:99-108.

23. Jakab GJ: Adverse effect of a cigarette smoke component, acrolein, on pulmonary antibacterial defenses and on viral-bacterial interactions in the lung. Am Rev Respir Dis 1977, 115:33-38.

24. Costa DL, Kutzman RS, Lehmann JR, Drew RT: Altered lung function and structure in the rat after subchronic exposure to acrolein. Am Rev Respir Dis 1986, 133:286-291.

25. Caron L, Karkazis K, Raffin TA, Swan G, Koenig BA: Nicotine addiction through a neurogenomic prism: ethics, public health, and smoking Nicotine Tob Res 2005, 7:181-197.

26. Totti N 3rd, McCusker KT, Campbell EJ, Griffin GL, Senior RM: Nicotine is chemotactic for neutrophils and enhances neutrophil responsiveness to chemotactic peptides. Science 1984, 223:169-171.

27. Lee LY, Gerhardstein DC, Wang AL, Burki NK: Nicotine is responsible for airway irritation evoked by cigarette smoke inhalation in men. $J$ App/ Physiol 1955-1961, 1993:75

28. Talhout R, Opperhuizen A, van Amsterdam JG: Role of acetaldehyde in tobacco smoke addiction. Eur Neuropsychopharmacol 2007, 17:627-636.

29. Sisson JH, Tuma DJ, Rennard SI: Acetaldehyde-mediated cilia dysfunction in bovine bronchial epithelial cells. Am J Physio/ 1991, 260:L29-L36.

30. Demedts IK, Demoor T, Bracke KR, Joos GF, Brusselle GG: Role of apoptosis in the pathogenesis of COPD and pulmonary emphysema. Respir Res 2006, 7:53.

31. Hoshino Y, Mio T, Nagai S, Miki H, Ito I, Izumi T: Cytotoxic effects of cigarette smoke extract on an alveolar type II cell-derived cell line. Am J Physiol Lung Cell Mol Physiol 2001, 281:L509-L516.

32. Kim H, Liu X, Kobayashi T, Conner H, Kohyama T, Wen FQ, Fang Q, Abe S, Bitterman P, Rennard SI: Reversible cigarette smoke extract-induced DNA damage in human lung fibroblasts. Am J Respir Cell Mol Biol 2004, 31:483-490.

33. Lan MY, Ho CY, Lee TC, Yang AH: Cigarette smoke extract induces cytotoxicity on human nasal epithelial cells. Am J Rhinol 2007, 21:218-223.

34. O'Brien GJ, Riddell G, Elborn JS, Ennis M, Skibinski G: Staphylococcus aureus enterotoxins induce IL-8 secretion by human nasal epithelial cells. Respir Res 2006, 7:115.

35. Comer DM, Elborn JS, Ennis M: Comparison of nasal and bronchial epithelial cells obtained from patients with COPD. PLoS One 2012, 7:e32924.

36. Lee WK, Ramanathan M Jr, Spannhake EW, Lane AP: The cigarette smoke component acrolein inhibits expression of the innate immune 
components IL- 8 and human beta-defensin 2 by sinonasal epithelial cells. Am J Rhinol 2007, 21:658-663.

37. Li L, Hamilton RF Jr, Taylor DE, Holian A: Acrolein-induced cell death in human alveolar macrophages. Toxicol Appl Pharmacol 1997, 145:331-339.

38. Valacchi G, Pagnin E, Phung A, Nardini M, Schock BC, Cross CE, van der Vliet A Inhibition of NFkappaB activation and IL-8 expression in human bronchial epithelial cells by acrolein. Antioxid Redox Signal 2005, 7:25-31.

39. Moretto N, Facchinetti F, Southworth T, Civelli M, Singh D, Patacchini R: Alpha, beta-unsaturated aldehydes contained in cigarette smoke elicit IL-8 release in pulmonary cells through mitogen-activated protein kinases. Am J Physiol Lung Cell Mol Physiol 2009, 296:L839-L848.

40. Greene CM, Ramsay H, Wells RJ, O'Neill SJ, McElvaney NG: Inhibition of Toll-like receptor 2-mediated interleukin-8 production in Cystic Fibrosis airway epithelial cells via the alpha7-nicotinic acetylcholine receptor. Mediators Inflamm 2010, 2010:423241.

41. Li Q, Zhou X, Kolosov VP, Perelman JM: Nicotine suppresses inflammatory factors in HBE16 airway epithelial cells after exposure to cigarette smoke extract and lipopolysaccharide. Trans/ Res 2010, 156:326-334.

42. Tsai JR, Chong IW, Chen CC, Lin SR, Sheu CC, Hwang JJ: Mitogen-activated protein kinase pathway was significantly activated in human bronchial epithelial cells by nicotine. DNA Cell Bio/ 2006, 25:312-322

43. Eiserich JP, van der Vliet A, Handelman GJ, Halliwell B, Cross CE: Dietary antioxidants and cigarette smoke-induced biomolecular damage: a complex interaction. Am J Clin Nutr 1995, 62:1490S-1500S.

44. Nardini M, Finkelstein El, Reddy S, Valacchi G, Traber M, Cross CE, van der Vliet A: Acrolein-induced cytotoxicity in cultured human bronchial epithelial cells. Modulation by alpha-tocopherol and ascorbic acid. Toxicology 2002, 170:173-185.

45. Yoon CH, Park HJ, Cho YW, Kim EJ, Lee JD, Kang KR, Han J, Kang D: Cigarette smoke extract-induced reduction in migration and contraction in normal human bronchial smooth muscle cells. Korean J Physiol Pharmacol 2011, 15:397-403.

46. Sandborn WJ: Nicotine therapy for ulcerative colitis: a review of rationale, mechanisms, pharmacology, and clinical results. Am J Gastroenterol 1999, 94:1161-1171.

47. Joe Y, Kim HJ, Kim S, Chung J, Ko MS, Lee WH, Chang KC, Park JW, Chung $\mathrm{HT}$ : Tristetraprolin mediates anti-inflammatory effects of nicotine in lipopolysaccharide-stimulated macrophages. J Biol Chem 2011, 286:24735-24742.

48. Sugano N, Shimada K, Ito K, Murai S: Nicotine inhibits the production of inflammatory mediators in U937 cells through modulation of nuclear factor-kappaB activation. Biochem Biophys Res Commun 1998, 252:25-28.

49. Dowling O, Rochelson B, Way K, Al-Abed Y, Metz CN: Nicotine inhibits cytokine production by placenta cells via NFkappaB: potential role in pregnancy-induced hypertension. Mol Med 2007, 13:576-583.

50. Cohen C, Bergis OE, Galli F, Lochead AW, Jegham S, Biton B, Leonardon J, Avenet P, Sgard F, Besnard F, Graham D, Coste A, Oblin A, Curet Q, Voltz C, Gardes A, Caille D, Perrault G, George P, Soubrie P, Scatton B: SSR591813, a novel selective and partial alpha4beta2 nicotinic receptor agonist with potential as an aid to smoking cessation. J Pharmacol Exp Ther 2003, 306:407-420.

51. Togo S, Sugiura H, Nelson A, Kobayashi T, Wang X, Kamio K, Kawasaki S, Bitterman P, Rennard SI, Liu X: Hepatic growth factor (HGF) inhibits cigarette smoke extract induced apoptosis in human bronchial epithelial cells. Exp Cell Res 2010, 316:3501-3511.

52. Sugiura H, Liu X, Togo S, Kobayashi T, Shen L, Kawasaki S, Kamio K, Wang XQ, Mao LJ, Rennard SI: Prostaglandin E(2) protects human lung fibroblasts from cigarette smoke extract-induced apoptosis via EP(2) receptor activation. J Cell Physiol 2007, 210:99-110.

53. Manzel LJ, Shi L, O'Shaughnessy PT, Thorne PS, Look DC: Cigarette smoke inhibition of the NF-\{kappa\}B-dependent response to bacteria in the airway. Am J Respir Cell Mol Biol 2011, 44:155-165.

54. Liu X, Togo S, Al-Mugotir M, Kim H, Fang Q, Kobayashi T, Wang X, Mao L, Bitterman P, Rennard S: NF-kappaB mediates the survival of human bronchial epithelial cells exposed to cigarette smoke extract. Respir Res 2008, 9:66

55. Wickenden JA, Clarke MC, Rossi AG, Rahman I, Faux SP, Donaldson K, MacNee W: Cigarette smoke prevents apoptosis through inhibition of caspase activation and induces necrosis. Am J Respir Cell Mol Biol 2003, 29:562-570
56. Groskreutz DJ, Monick MM, Babor EC, Nyunoya T, Varga SM, Look DC, Hunninghake GW: Cigarette smoke alters respiratory syncytial virus-induced apoptosis and replication. Am J Respir Cell Mol Biol 2009, 41:189-198.

57. Kaushik G, Kaushik T, Khanduja S, Pathak CM, Khanduja KL: Cigarette smoke condensate promotes cell proliferation through disturbance in cellular redox homeostasis of transformed lung epithelial type-II cells. Cancer Lett 2008, 270:120-131.

58. Grasl-Kraupp B, Ruttkay-Nedecky B, Koudelka H, Bukowska K, Bursch W, Schulte-Hermann R: In situ detection of fragmented DNA (TUNEL assay) fails to discriminate among apoptosis, necrosis, and autolytic cell death: a cautionary note. Hepatology 1995, 21:1465-1468.

59. Leist $M$, Jaattela M: Four deaths and a funeral: from caspases to alternative mechanisms. Nat Rev Mol Cell Biol 2001, 2:589-598.

doi:10.1186/1471-2466-14-32

Cite this article as: Comer et al:: Inflammatory and cytotoxic effects of acrolein, nicotine, acetylaldehyde and cigarette smoke extract on human nasal epithelial cells. BMC Pulmonary Medicine 2014 14:32.

\section{Submit your next manuscript to BioMed Central and take full advantage of:}

- Convenient online submission

- Thorough peer review

- No space constraints or color figure charges

- Immediate publication on acceptance

- Inclusion in PubMed, CAS, Scopus and Google Scholar

- Research which is freely available for redistribution 